VILMA HAYDEE AROVICH DE BOGADO

\title{
LA LEYENDA SOBRE VIRGILIO EN UN PASAJE DEL LIBRO DE BUEN AMOR
}

\section{1.- Punto de partida.}

En la extensa reprensión que hace el Arcipreste a Don Amor le atribuye, a partir de la estrofa 257 , el pecado de la lujuria; yuxtapone d os ejemplos ilustradores de su diatriba, el segundo de los cuales (estr. 261-268) presenta la figura de Virgilic como protagonista de una aventura amorosa:

"Al sabidor Virgilio, como dize en el testo, engañólo la dueña, quando l' colgó en el cesto, cuidando que l' subié a su torre por esto.

Pcrque l' fizo desonra ë escarnio del ruego el grand encantador fízole muy mal juego: la luz de la candela encantó ë el fuego, que quantö era en Roma en punto morió luego;

assi que los romanos, fasta la criatura, non podién aver fuegc, por su desaventura, si non lö encendían dentrö en la natura de la mujer mesquina; otro non les atura:

si dava üno a otro fuegö o la candela, amatávase luego; venién todos a ella, encendién allí todos comö en grand centella. Assí vengó Virgilio su desonra e querella.

Después desta desonra e de tanta vergüeña, desencantó êl fuego, quë ardiesse en la leña. Por fazer su loxuria Vergiliö en la dueña fizo otra maravilla qu' el omne nunca ensueña:

todo el suelo del ríc de la cibdat de Roma, Tiberic, agua cabdal, que muchas aguas toma, fízol suelo de cobre: reluze más que goma; a dueñas tu loxuria desta guisa las doma. 
Desque pecó con ella, sentiósë escarnida: mandó fer escalera de tornö, enxerida de navajas agudas, porquë, a la subida que subiesse Vergilio, acabasse su vida;

él sopo que era fecho, por sü escantamente: nunca más fue ä ella, nin la ovo talente. Assí por la loxuria es verdaderamente el mundö escarnido e muy triste la gente".

(Libro de Buen Amor, estr. 261-268)(1)

\section{2.- Virgilio y las leyendas medievales.}

El pasaje que nos ocupa no es extraño a una corriente medieval de pensamiento que trata de aunar las raíces clásico-paganas de la cultura occidental con la moral y el pensamiento cristianos; en este sentido se intenta una explicación alegórica de los antiguos que permite rescatarlos para el mundo cristiano e interpretarlos como prefiguración de éste. Asimismo se popularizan figuras tanto de poetas y filósofos como de héroes de las gestas griegas y romanas, las que, anacrónicamente insertas en la cultura medieval, se presentan como paradigmas de virtud o como protagonistas de sucesos aleccionadores. En España, Eneas, Héctor, Aquiles, se convierten en personajes tan estimados como Virgilio, Platón, Aristóteles y Sócrates entre otros; estos últimos son conocidos no sólo por sus obras y sus doctrinas sino también por las numerosas anécdotas legendarias con las que la ficción ha ilustrado sus vidas.

Virgilio, dada su condición de poeta que el hombre medieval confunde con la de filósofo, adquiere fama de sabio; por ello es que el Dolophatos sive de Rege et septem sapientibus, versión latina del Sendebar y fuente del Libro de los siete sabios de Roma, presenta a Virgilio como maestro a quien el rey confía la educación de su hijo. La leyenda se hará cargo de esta condición y lo mostrará capaz no sólo para hallar solución acertada a todas las situaciones en que la vida coloca a los mortales sino también para interpretar las cosas sobrenaturales. Este último aspecto de su sabiduría lo muestra a veces como profeta (posiblemente por influencia del controvertido anuncio de la Bucólica IV), y otras como mago que ejecuta maravillcsas transformaciones o encantamientos. Resulta imposible establecer con precisión, a pesar de las conjeturas hechas al respecto, cuándo se confieren estos poderes mágicos al poeta y cuáles son las circunstancias que propician esta metamorfosis; uno de los primeros indicios de la transformacion es un texto del siglo XII, el Polycraticus de Jean de Salisbury. Sin embargo, el análisis de la bibliografía en la cual aparece la leyenda virgiliana, permite afirmar a Jean Céard (2) que la figura de Virgilic profeta es anterior a la del mago, y ésta a la del nigromántico. Cabe destacar que al retrato del mago, en ocasiones, se agrega el atributo de la lujuria.

El personaje en su relación con el amor es la única faceta legendaria que recogerá hacia el final de la Edad Media el Romiancero,.el cual, con el nombre de Vergilios, lo presentará como un caballero enamoradizo y palaciego cuando ya se hayan olvidado sus poderes mágicos y gran sabiduria. 


\section{3.- "Aquí fabla del pecado de la luxuria".}

Hablando de la lujuria Juan Ruiz echa mano a un ejemplo que es probable que fuera conocido por sus coetáneos a través de algún texto escrito como se desprende del segundo verso de la estrofa 261: "Al sabidor Virgilio, como dize en el testo...". Con esta expresión se intenta otorgar al relato cierto grado de autenticidad $\mathrm{y}$ garantizar el apoyo de una fuente (aunque sólo se la mencione en forma muy vaga), de acuerdo con la actitud medieval que menosprecia la libre invención.

En una primera lectura del pasaje podemos señalar claramente dos episodios: a) la burla de la dueña; b) la venganza. Ambos aparecen registrados desde muy antiguo en la historia de la literatura y aunque aquí se encuentren unidos, como ocurre en un texto latino del siglo XIII y en relatcs franceses, italianos, alemanes e ingleses a partir del siglo XIV, sabemos que han tenido vida autónoma y que ha sido posible registrarlos por separado. Comparetti (3) rastrea las fuentes de cada uno de los episodios mencionados y ofrece versiones ilustrativas de los mismos.

\subsection{La burla de la dueña.}

La imagen del sabio en la cesta suspendida de una torre y expuesto a las burlas de todos por el ardid de una mujer es un motivo conocido en la literatura europea de los siglos XIII y XIV. Nuestro texto reduce el suceso sólo a los dos últimos versos de la estr. 261 que de esta manera se convierten, a pesar de su parquedad, en una apretada pero completa sintesis de un relato mucho más extenso.

\subsubsection{La actitud didáctica.}

María Rosa Lida señala este relato como una repetidísima conseja que, tal como el Lai d'Aristote, puede considerarse un cuento de tipo erudito como los que utilizaban los predicadores(4). Este concepto resalta la intención didáctica la cual, en efecto, se desprende del hecho de que Juan Ruiz la incluya como ejemplo aleccionador.

En el segundo verso de la estrofa 261 se alude al "sabidor Virgilio"; esta mención no es casual y está relacionada con la intención didáctica. Algunas versiones de la anécdota señalan a Hipócrates como víctima del humillante engaño. Lo que interesa en ambos casos es destacar la sabiduria del personaje la cual ayuda a resaltar el riesgo que entrañan los peligrosos ardides de las mujeres desde el momento en que logran atrapar a sabios tan respetados. Asimismo, queda claro que el hombre sólo demuestra ser realmente sabio cuando es capaz de sobreponerse a la astucia femenina, cosa que. en nuestro caso, Virgilio logrará en la segunda parte del relato.

\subsubsection{La actitud antifeminista.}

Paralela a la incención didáctica se advierte en el episodio de la cesta 
una marcada actitud antifeminista la cual no es extraña a la literatura medieval española y está representada, entre otros, por el Sendebar, colección oriental conocida en tiempos de Juan Ruiz y vertida al castellano con el nombre de Libro de los engaños e los asayamientos de las mujeres a mediados del siglo XIII. En el pasaje que nos ocupa la mujer es señalada sólo como una dueña, en tanto que en otras versiones europeas del suceso (5) es hija del emperador de Roma; no obstante la acción transcurre en esta ciudad como vemos más adelante (estr. 262 y 266).

A pesar de la parquedad del narrador con respecto a la protagonista no es difícil advertir en ella dos caracteres comunes a la corriente misógina ya señalada: en primer lugar, se la presenta como objeto de tentación y causa determinante del escarnio del hombre; en segundo lugar se destaca su habilidad para engañar a quienes se le acercan con requerimientos amorosos.

\subsection{La venganza.}

Este segundo momento del ejenıplo resulta consecuencia natural y necesaria del engaño femenino; la deshonra infligida al protagonista a partir de la vergüenza experimentada al verse burlado, es el rescrte desencadenante de las represalias como se consigna en el primer verso de la estrofa 262. Sin embargo, hacia fines del siglo $X V$, cuando La Celestina mencione la misma conseja de Virgilio colgado en la cesta pondrá especial cuidado en señalar que a pesar de ello el sabio no se sintió deshonrado ni perdió "el nombre de Virgilio" (6), idea que prefigura la nueva actitud erasmista que concede honor al ser humano por los valores que le son inherentes y no a partir de las opiniones ajenas.

Puede estructurarse esta segunda parte del relato a la vez en dos escenas: a) las venganzas del indignado sabio; b) la frustrada venganza de la dueña.

\subsubsection{Las venganzas del sabio y la actitud ante lo fantástico.}

En el afán de reparar la humillación sufrida Virgilio lleva a cabo dos represalias. La primera de ellas consiste en la extinción del fuego de la ciudad el cual sólo puede ser encendido en las entrañas de la mujer que lo ha desdeñado; el castigo es terrible. El motivo es conocido en la literatura europea y en ella aparece registrado probablemente desde el siglo VIII, atribuido al mago Eliodoro.

Con la segunda represalia, que carece de la popularidad de la anterior, Virgilio transforma el lecho del Tíber en cobre con lo cual el río adquiere un aspecto resplandeciente. Este prodigio no ha logrado la divulgación que alcanzó el encantamiento del fuego y Julio Cejador y Frauca considera que puede obedecer a una confusión del narrrader con otro hecho que menciona la leyenda y que es la construcción de un puente de bronce (7). Se atribuyen no obstante a Virgilio otros prodigios que estarian relacionados con éste en tanto que le permiten crear o convertir objetos en metal; 
asi por ejemplo la creación de un hombre de cobre para que cumpla funciones de guardián. Este personaje, que es casi un autómata, nos hace pensar en la legendaria figura de Talos; en relación con esta última y con la transformación de objetos en metal, advirtamos que Vladimir Propp, quien señala motivos del folklore ruso que aparecen también en la literatura clásica, hace referencia a un monstruo silvestre al cual se lo identifica como Frente de Cobre; de él nos dice que suele aparecer en los cuentos maravillosos del folklore ruso y que, como su nombre lo señala, se destaca por su color cúprico, a veces dorado, aspecto que lo vincula con el fuego y con el sol; al contacto con este personaje, los objetos se transforman en oro o adquieren la apariencia de este metal; algo análogo a lo que ocurrió a Midas, el rey frigio que convertía en oro cuanto tocaba (8).

Con estos encantamientos la figura de Virgilio se afianza en su carácter de mago lujurioso y terrible que maneja a su antojo aun la luz y el fuego y es capaz de emplear sus poderes para satisfacer venganzas personales; estos caracteres negativos se incorporarán a su retrato tiempo después de que la leyenda, ya enriquecida y ampliada, lo mostrara como mago, pues en sus comienzos, la magia que se le atribuía carecía de connotaciones diabólicas.

Sabemos que la literatura española no gusta ni tampoco abusa de lo maravilloso y lo fantástico. Desde los orígenes de las gestas y de las cancioncillas líricas hasta el declinar de la Edad Media sólo podriamos señalar escasísimos ejemplos y no todos ellos se incluirian estrictamente dentro de tal esfera. Emilio Carilla advierte que en la España cristiana lo fantástico se circunscribe al milagro o a la visión del trasmundo, pero como consecuencia de la secular convivencia con los árabes y de la influencia de la literatura oriental, se enriquece notablemente la temática fantástica y se introduce la magia o la hechiceria (9).

Los encantamientos realizados por Virgilio nos trasladan de la burla de la cesta, desarrollada en el ámbito de lo cotidiano, al plano de lo fantástico. Precisamente, es necesaria la irrupción de lo fantástico para que sobre la figura del personaje histórico florezca la leyenda. La posibilidad de articulación de ambos planos (realidad- fantasia) a nivel del relato elegido por Juan Ruiz radica exclusivamente en los poderes mágicos del protagonista.

Es conveniente hacer algunas consideraciones con respecto a la actitud con que el hombre medieval asume lo mágico; para esto se hace necesario señalar que los teólogos medievales y algınos doctores de la iglesia como por ejemplo Santo Tomás, aceptan la realidad de la magia. A esta corriente que adquiere consistencia a partir del siglo XIV en todo el ámbito de Europa, se opone, naturalmente, la posición de los escépticos como Nicolás de Oresme. Sin embargo las medidas de la iglesia tendientes a contrarrestar el notable desarrollo de las artes ocultas y prácticas hechiceriles (llevadas a cabo en algunos casos por los mismos clérigos) así como la existencia de manuales de magia tanto en latín como en los idiomas vernáculos, corroboran la gravitación de lo mágico en la vida cotidiana del hombre medieval. España no se sustrae a este fenómeno, y para no abundar en ejemplos recordemos simplemente la fama que Salamanca y Toledo alcan- 
zaron como centros en los cuales se podía estudiar seriamente la magia, y precisamente un coetáneo de Juan Ruiz, el Infante Don Juan Manuel, va a inmortalizar esta fama en el conocido enxiemplo "de lo que conteçió a un deán de Sanctiago con don Illán, el grand maestro de Toledo"; y no podemos dejar de mencionar que en Les Faictz Merveilleux de Virgilie, se muestra a éste como estudiante de nigromancia en Toledo.

Volviendo a Juan Ruiz, señalemos que recurre a la leyenda para sostener su argumentación contra el pecado de lujuria y de esta manera se introduce lo fantástico supeditado a su finalidad didáctica.

\subsubsection{La venganza de la dueña.}

El episodio que se habia iniciado con la burla de la mujer finaliza con una frustrada artimaña de la misma dueña con la cual volvemos al plano de lo real; intenta dar muerte a Virgilio pero su objetivo no se concreta puesto que ahora sí, luego de la humillante burla de la cesta, el sabio se comporta como tal; ha aprendido en su propia experiencia y puede advertir el peligro que lo acecha a tiempo para sortearlo.

\section{Conclusión.}

La figura de Virgilio aparece en el episodio del Libro de Buen Amor que acabamos de analizar con los caracteres de sabio y de mago lujurioso que le habian conferido las leyendas medievales.

El relato que no es original de Juan Ruiz y fue conocido en Europa antes de su incorporación al texto que nos ocupa, manifiesta una clara actitud antifeminista y burlesca, pero su inclusión, con el objeto de ilustrar y reforzar la argumentación que el narrador expone frente a Don Amor, obedece a una finalidad predominantemente didáctica. 


\section{NOTAS}

1.- Cito según edición crítica de Joan Corominas, Gredos, Madrid, 1973, p. 155-157.

2.- Céard, J. "Virgile, un grand homme soupçonné de Magie" en Présence de Virgile, Paris, 1978, p.265-278.

3.- Comparetti,D. Virgilio nel Medio Evo. La Nuova Italia. Firenze. 1967, T. 2, cap. VIII.

4.- Lida, Maria Rosa. El cuento popular, Losada, Bs. As., 1976, p. 43.

5.- Comparetti, D. Ob. cit.

6.- Rojas, Fernando de. La Celestina. Espasa Calpe, Madrid, 1968, v. I. p. 243 s.

7.- Nota correspondiente de Julio Cejador y Frauca en su edición del $\mathrm{Li}$ bro de Buen Amor, Espasa Calpe, Madrid, 1954.

8.- Propp, Vladimir. Las raíces folklóricas del cuento, Ed. Fundamentos, Madrid, 1979 , p. 228 ss

9.- Carilla, Emilio. "Los árabes y la literatura fantástica en España"en Literatura Española I, Universidad Nacional de Tucumán, 1971. 


\section{BIBLIOGRAFIA}

1.- Juan Ruiz. Libro de Buen Amor. Ed. critica de Joan Corominas. Gredos, Madrid, 1973.

2.- Juan Ruiz. Libro de Buen Amor. Ed. de Julio Cejador y Frauca. Espasa Calpe, Madrid, 1954.

3.- Domenico Comparetti. Virgilio nel Medio Evo. T. II "Virgilio nela leggenda popolare". La Nuova Italia, Firenze, 1967.

4.- José Antonio Maravall. "La estimación de Sócrates y de los sabios clásicos en la Edad Media española" en Estudios del pensamiento español. Ed. Cultura Hispánica, Madrid, 1967.

5.- Jean Céard. "Virgile, un grand homme soupçonné de Magie" en Présence de Virgile. Actes du Colloque des 9, 11 et 12 Décembre 1976 (Paris E.N.S., Tours). Université de Tours. Institut d'etudes latines et Centre de Recherches. Société d'edition "Les Belles Lettres", Paris, 1978.

6.- María Jesús Lacarra. Cuentística Medieval en España. Universidad de Zaragoza, 1979.

7.- Carmelo Gariano. El mundo poético de Juan Ruiz. Gredos, Madrid, 1974.

8.- Emilio Carilla. "Los árabes y la literatura fantástica en España" en Literatura Española I, Universidad Nacional de Tucumán, 1971.

9.- Francisco López Estrada. Introducción a la literatura medieval española. Gredos, Madrid, 1970.

10.- Peter E. Rusell. "La Magia, tema integral de la Celestina" en Temas de La Celestina. Ariel, Barcelona, 1978.

11.- Vladimir Propp. Las raices folklóricas del cuento. Ed. Fundamentos, Madrid, 1979.

12.- Maria Rosa Lida. El cuento popular. Losada, Bs. As., 1976. 